\title{
How does the dengue vector mosquito Aedes albopictus respond to global warming?
}

Pengfei Jia', Xiang Chen ${ }^{2,3^{*}}$, Jin Chen, Liang Lư ${ }^{4}$ Qiyong Liu ${ }^{4}$ and Xiaoyue Tan ${ }^{1}$

\begin{abstract}
Background: Global warming has a marked influence on the life cycle of epidemic vectors as well as their interactions with human beings. The Aedes albopictus mosquito as the vector of dengue fever surged exponentially in the last decade, raising ecological and epistemological concerns of how climate change altered its growth rate and population dynamics. As the global warming pattern is considerably uneven across four seasons, with a confirmed stronger effect in winter, an emerging need arises as to exploring how the seasonal warming effects influence the annual development of Ae. albopictus.

Methods: The model consolidates a 35-year climate dataset and designs fifteen warming patterns that increase the temperature of selected seasons. Based on a recently developed mechanistic population model of Ae. albopictus, the model simulates the thermal reaction of blood-fed adults by systematically increasing the temperature from 0.5 to $5^{\circ} \mathrm{C}$ at an interval of $0.5^{\circ} \mathrm{C}$ in each warming pattern.

Results: The results show the warming effects are different across seasons. The warming effects in spring and winter facilitate the development of the species by shortening the diapause period. The warming effect in summer is primarily negative by inhibiting mosquito development. The warming effect in autumn is considerably mixed. However, these warming effects cannot carry over to the following year, possibly due to the fact that under the extreme weather in winter the mosquito fully ceases from development and survives in terms of diapause eggs.

Conclusions: As the historical pattern of global warming manifests seasonal fluctuations, this study provides corroborating and previously ignored evidence of how such seasonality affects the mosquito development. Understanding this short-term temperature-driven mechanism as one chain of the transmission events is critical to refining the thermal reaction norms of the epidemic vector under global warming as well as developing effective mosquito prevention and control strategies.
\end{abstract}

Keywords: Aedes albopictus, Mosquito, Global warming, Seasonality, Mechanistic population modeling, Thermal reaction norms

\section{Background}

How global warming potentially influences vectorborne diseases has prompted great concerns from both the general public and ecological scientists $[1,2]$. Dengue fever, known as the most prevalent mosquito-borne epidemic, generates 50-100 million

\footnotetext{
*Correspondence: chenxiangpeter@gmail.com

${ }^{2}$ State Key Laboratory of Earth Surface Processes and Resource Ecology,

Beijing Normal University, Beijing 100875, China

${ }^{3}$ Department of Emergency Management, Arkansas Tech University,

Russellville 72801, AR, USA

Full list of author information is available at the end of the article
}

cases per year and is constantly growing with the expansion of urban residence, increased air travel and the growth of global population [2-5]. In addition to human-induced factors, the observed global warming trend plays a potential role in the generation and transmission of the disease [6]. The complex interplay between global warming and dengue viruses has been a subject of debate yet to be fully understood; one critical component in the long chain of transmission events is the altered population dynamics of the vector, Aedes albopictus, commonly known as the 
Asian Tiger mosquito [7-10]. Understanding how Ae. albopictus responds to global warming underscores the need to develop effective strategies to mitigate and control dengue and other mosquito-borne epidemics.

Ae. albopictus is native to the humid tropics of Southeast Asia [11]. With an increasing pace of globalization, the mosquito expanded its habitat to other continental regions, including East Asia, Europe, Africa, the Middle East and the Americas [6, $9,11]$. With an observed warmer global pattern in the last several decades, Ae. albopictus has geographically shifted from its original habitats $[12,13]$. Specifically, the presence of the mosquito surged in certain high-latitude temperate areas, such as central north-western European and Balkan countries [14, 15]. The emergence was attributed to the rising local temperature, giving rise to more conductive habitats and lengthened activity periods that allowed for an improved rate of success in overwintering [14]. In addition, field observations confirmed a decline in the density of the species in areas with a recorded dry and warm summer, such as southern Spain and Sardinia [14]. This decline was explained by the rising temperature rendering the previously favored habitats less suitable $[14,16]$. These contrasting responses displayed a potential geographical shift due to changes in mosquito habitats and behaviors as a result of warmer temperatures. These empirical studies further provided evidence for predicting the regional sustainability of the mosquito and controlling their infestation in areas of prevalence.

A step forward to accommodate these observations is to identify the climatic conditions that affect Ae. albopictus growth. In most world regions, temperature plays a dominating role in the development of the species, along with precipitation and photoperiod [17]. There has been a long tradition in biological research on the relationship between climatic factors and population dynamics of $A e$. albopictus, using controlled laboratory experiments [18-20]. It is generally accepted that moderate-tohigh temperatures expedite selected stages of the development, while shortening the lifespan of adult mosquitoes [21, 22]. These structured relationships have been incorporated in temperature-driven empirical models to demarcate areas suitable for mosquito development under projected future warming scenarios [14].

One element missing in the discussion is how global warming affects the mosquitoes' life cycle in terms of different growth stages. This issue is introduced by two existing gaps in the research on the climate-driven nature of the Ae. albopictus population. First, although many studies are able to identify the favorable conditions for development, the contingencies between growth stages are often overlooked. The complete life cycle of the Ae. albopictus is a chain of events differing in morphology and natural habitats. Existing studies using controlled experiments and statistical modeling are invariably centered on limited growth stages (e.g. larvae, pupae), while the intrinsic connections between stages are ignored. Secondly, although a wide discussion arises regarding the projection of climatic suitability for the growth of mosquito in the context of global warming $[13,14,16,20]$, the seasonality of development (i.e. the population variance on a seasonal basis) rendered by warming effects has received very little attention to date. This issue is of great importance as the global warming pattern is considerably uneven across four seasons, with the greatest warming effect at high-latitudes in winter $[23,24]$. Thus, an emergent need is to develop a rigorous mathematical model that illuminates the seasonal and stage-specific relationship and thus provides evidence for excavating how the mosquito responds to the heterogeneity of global warming.

Based on a recently proposed mechanistic population model [25], this study examines the theoretical thermal reaction of Ae. albopictus adults over four seasons of a year. By incorporating a 35-year historical dataset into the model, the study identifies critical metrics about the mosquito development. This study aims to provide a tentative answer to the effects of seasonality on Ae. albopictus, while shedding light on the assessment of the epidemic vector's sustainability in a regional context.

\section{Methods}

\section{Study area and data}

The case study was conducted in Guangzhou, China $\left(23^{\circ} 17^{\prime} \mathrm{N}, 113^{\circ} 23^{\prime} \mathrm{E}\right)$. Guangzhou, a transportation port located in south-western China, is the third largest city in the country. Guangzhou is under a typical subtropical climate with a humid, hot summer and a mild winter. The peculiar climate has created favorable conditions for mosquitoes to hatch and develop, giving rise to widespread cases of mosquito-borne diseases. The number of dengue cases in Guangzhou over the first 11 months of 2014 was 37,305 , accounting for $70.75 \%$ of the cumulative cases since 1978 [26]. The sudden outbreak of dengue drew the public attention of its peridomestic vector to a heightened extent [27]. In a previous study, we established a climate-driven population model of Ae. albopictus [25]. Built upon this model, this study attempts to answer a broader question of 
how the mosquito responds to the temperature rise in the last four decades. To achieve this goal, we collected a 35-year climatic dataset based on one observation station in Guangzhou. The datasets included daily mean temperature and daily accumulative precipitation over 1980-2014 from the China Meteorological Data Sharing Service System [28]. Data of photoperiod were derived from the National Oceanic and Atmospheric Administration [29] with respect to the geographical coordinates of Guangzhou. These datasets were incorporated into the model to simulate the theoretical thermal reaction of Ae. albopictus under different warming scenarios.

\section{Mechanistic population model of Ae. albopictus}

The mechanistic population model is different from the traditional statistical model, in that it formulates the successive development of the species in a bottom-up approach $[25,30]$. In a mechanistic population model, an individual behavior (e.g. egg hatching) can be described by a mathematical equation (invariably in the form of a differential equation). By combining equations with each representing a single but related behavior, a mechanistic model is able to demonstrate and explain how the dependent variables affect the outcome at each phase of the development [30-32].

The model employed in the study is termed the mechanistic population model of Ae. albopictus with diapause (MPAD). The model was developed by Jia et al. [25] to characterize the population dynamics of Ae. albopictus at different growth stages of its life cycle. The mosquito's life cycle can be broadly dichotomized into the aquatic period and the aerial period with different compartments [33]. The MPAD model establishes a seven-stage life cycle, including eggs (diapause $E_{0}$ and non-diapause $E_{\mathrm{dia}}$ ), larvae $(L)$, pupae $(P)$, emerging adults $\left(A_{\mathrm{em}}\right)$, bloodfed adults $\left(A_{\mathrm{b}}\right)$, gestating adults $\left(A_{\mathrm{g}}\right)$ and ovipositing adults $\left(A_{\mathrm{r}}\right)$. These stages are formulated by a set of seven differential equations to describe the successive development process of Ae. albopictus, as shown in Eq. (1). The parameters included in the equation are given in Table 1. In Eq. (1), the dependent variable of each differential equation denotes the daily variation of population abundance at a specific life stage. The climate-independent parameters in Table 1 are primarily driven by three climatic factors: daily mean temperature $(T)$, daily accumulative precipitation $(P P)$ and daily photoperiod $(S D)$. Table 2 summarizes the relationship between these parameters and the climatic factors.

A major contribution of the model is the consideration of diapause, referred to as the state of the
Table 1 Notation of the MPAD model parameters

\begin{tabular}{|c|c|}
\hline \multicolumn{2}{|c|}{ Climate-dependent parameter } \\
\hline$\overline{f_{\mathrm{E}}}$ & Non-diapause egg hatching rate $\left(\right.$ day $\left.^{-1}\right)$ \\
\hline$f_{\text {dia }}$ & Diapause egg hatching rate $\left(\right.$ day $\left.^{-1}\right)$ \\
\hline$f_{L}$ & Larval development rate $\left(\right.$ day $\left.^{-1}\right)$ \\
\hline$f_{\mathrm{p}}$ & Pupal development rate $\left(\right.$ day $\left.^{-1}\right)$ \\
\hline$m_{\llcorner}$ & Larval mortality rate $\left(\right.$day $\left.^{-1}\right)$ \\
\hline$m_{\mathrm{P}}$ & Pupal mortality rate $\left(\right.$ day $\left.^{-1}\right)$ \\
\hline$m_{\mathrm{A}}$ & Adult mortality rate $\left(\right.$ day $\left.^{-1}\right)$ \\
\hline$\beta$ & Oviposition rate by each female $\left(\right.$ day $\left.^{-1}\right)$ \\
\hline$f_{\mathrm{Ag}}$ & Gestating adult development rate $\left(\right.$ day $\left.^{-1}\right)$ \\
\hline$k_{\mathrm{L}}$ & Environmental carrying capacity for larvae $\left(\mathrm{ha}^{-1}\right)$ \\
\hline$k_{p}$ & Environmental carrying capacity for pupae $\left(\right.$ ha $\left.^{-1}\right)$ \\
\hline$z_{1}$ & Binary function for diapause eggs oviposited \\
\hline$z_{2}$ & Binary function for diapause egg hatching \\
\hline$z_{\text {dia }}$ & $\begin{array}{l}\text { Binary function for adult activity during } \\
\text { the diapause }\end{array}$ \\
\hline \multicolumn{2}{|c|}{ Climate-independent parameter } \\
\hline$m_{E}$ & Non-diapause egg mortality rate $\left(\right.$ day $\left.^{-1}\right)$ \\
\hline$m_{\text {dia }}$ & Diapause egg mortality rate $\left(\right.$ day $\left.^{-1}\right)$ \\
\hline$\sigma$ & Percentage of females at emergence stage \\
\hline$\mu_{e m}$ & Emerging adult mortality rate $\left(\right.$ day $\left.^{-1}\right)$ \\
\hline$\mu_{r}$ & $\begin{array}{l}\text { Adult mortality rate related to seeking } \\
\left.\text { behavior (day }{ }^{-1}\right)\end{array}$ \\
\hline$\gamma_{\text {Aem }}$ & Emerging adult development rate $\left(\right.$ day $\left.^{-1}\right)$ \\
\hline$\gamma_{A B}$ & Blooding adult development rate $\left(\right.$ day $\left.^{-1}\right)$ \\
\hline$\gamma_{A O}$ & Ovipositing adult development rate $\left(\right.$ day $\left.^{-1}\right)$ \\
\hline
\end{tabular}

mosquito eggs being dormant and unable to hatch under extreme weather and desiccation [34, 35]. The model formulates egg diapause with a binary variable $\left(z_{\mathrm{dia}}\right)$ and related growth parameters, such as mortality rate $\left(m_{\text {dia }}\right)$ and development rate $\left(f_{\text {dia }}\right)$. As the adult mosquitoes become naturally eradicated when the temperature drops under $9.5{ }^{\circ} \mathrm{C}$ [36], the model assumes that this is the thermal threshold of diapause. Thus the model identifies the day of year (DOY) when the diapause begins and ends, eventually establishing the temperature-driven mechanism for egg/larva/pupa abundance based on their mortality rate and development rate. Through validation by the container index (CI) data collected from two Chinese cities over two respective 5-year periods (i.e. Guangzhou over 2007-2011 and Shanghai over 2009-2013), the model has achieved a relatively good fitting (i.e. correlation coefficient $r=0.84$ for Guangzhou and $r=0.90$ for Shanghai) [25]. The code of the model is provided in the reference [37]. 
Table 2 Relationship between climate-dependent parameters and climatic factors

\begin{tabular}{|c|c|}
\hline Parameter & Equation \\
\hline$f_{\mathrm{E}}$ & $f_{\mathrm{E}}(T)=0.5070 \exp \left[-\left(\frac{T-30.85}{12.82}\right)^{2}\right]$ \\
\hline$f_{\text {dia }}$ & $f_{\text {dia }}(T)=0.1 * 0.5070 \exp \left[-\left(\frac{T-30.85}{12.82}\right)^{2}\right]$ \\
\hline$f_{\mathrm{L}}$ & $f_{\mathrm{L}}(T)=0.1727 \exp \left[-\left(\frac{T-28.40}{10.20}\right)^{2}\right]$ \\
\hline$f_{\mathrm{p}}$ & $f_{\mathrm{P}}(T)=0.6020 \exp \left[-\left(\frac{T-34.29}{15.07}\right)^{2}\right]$ \\
\hline$m_{\llcorner}$ & $m_{\llcorner}(T)=\min \left\{1, \frac{1}{\left|-0.1305 T^{2}+3.868 T+30.83\right|}\right\}$ \\
\hline$m_{p}$ & $m_{P}(T)=\min \left\{1, \frac{1}{\left|-0.1502 T^{2}+5.057 T+3.517\right|}\right\}$ \\
\hline$m_{\mathrm{A}}$ & $m_{A}(T)=\min \left\{1, \frac{1}{\left|-0.1921 T^{2}+8.147 T-22.98\right|}\right\}$ \\
\hline$\beta$ & $\beta(T)=\max \left\{0,-0.0162 T^{2}+1.289 T-15.837\right\}$ \\
\hline$f_{\mathrm{Ag}}$ & $f_{\mathrm{Ag}}(T)=\max \left\{0, \frac{T-10}{77}\right\}$ \\
\hline$k_{\mathrm{L}}$ & $k_{L}\left(P P_{\text {norm }}\right)=k_{L}\left(1+P P_{\text {norm }}\right)$ \\
\hline$k_{\mathrm{p}}$ & $k_{P}\left(P P_{\text {norm }}\right)=k_{P}\left(1+P P_{\text {norm }}\right)$ \\
\hline$z_{1}$ & $\begin{array}{l}z_{1}\left(T_{\text {ave, }} S D_{\text {ave }}\right)= \\
\left\{1, T_{\text {ave }}(t)<21^{\circ} \mathrm{C} \text { and } S D_{\text {ave }}(t)<13.5 h, t_{\text {eggBegin }}<t<t_{\text {diaBegin }} 0 \text {, otherwise }\right.\end{array}$ \\
\hline$z_{2}$ & $\begin{array}{l}\mathrm{z}_{2}\left(T_{\text {ave, }} S \mathrm{SD}_{\text {ave }}\right)= \\
\left\{1, T_{\text {ave }}(t)>10.5^{\circ} \mathrm{C} \text { and } S D_{\text {ave }}(t)>10.25 h, t_{\text {diaEnd }}<t<t_{\text {eggend }} 0 \text {, otherwise }\right.\end{array}$ \\
\hline$z_{\text {dia }}$ & $\begin{array}{l}z_{2}\left(T_{\text {ave }} S D_{\text {ave }}\right)= \\
\left\{1, T_{\text {ave }}(t)<9.5^{\circ} \mathrm{C}, t>t_{\text {diaBegin }} \text { or } t<t_{\text {diaEnd }} 0 \text {, otherwise }\right.\end{array}$ \\
\hline
\end{tabular}

Abbreviations: $T$ daily mean temperature, $P P_{\text {norm }}$ rainfall over a 2-week period, normalized between 0 and 1 [32], $T_{\text {ave }} 7$-day averaged daily mean temperature, $S D_{\text {ave }}$ 7-day averaged daily sunlight hour, $t_{\text {eggBegin }}$ the time when diapause eggs emerge, $t_{\text {eggEnd }}$ the time when diapause eggs finish hatching, $t_{\text {diaBegin }}$ the time when diapause period begins, $t_{\text {diaEnd }}$ the time when diapause period ends

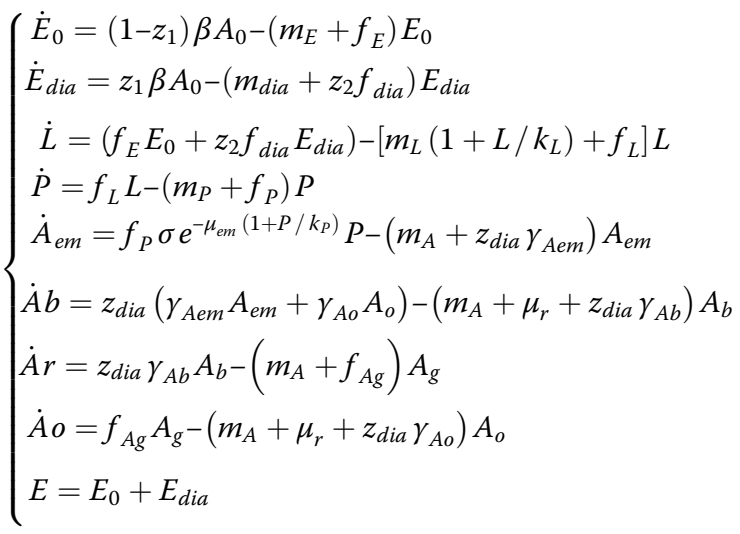

\section{Temperature data preprocessing}

As the long-term climate manifests a high degree of variability, we consolidated the 35-year data into a single year to represent the typical annual climatic conditions. Equation (2) gives the formula for the average daily temperature $\left(T_{\mathrm{j}}\right)$ on the $j$ th day of the consolidated year, along with its graphic shown in Fig. 1a. We also derived the average standard deviation of the daily mean temperature in the same manner, as shown in Fig. 1b. The standard deviation of the temperature is used to support the degree of temperature increase in the follow-up simulations.

$$
T_{j}=\frac{1}{35} \sum_{i=1}^{35} T_{j}^{i}, j=1, \ldots, 365
$$

Using the temperature of a single year does not suffice to test the warming effect, as in simulation models the result is largely influenced by the initial configuration of temperatures [25, 30, 32]. Thus, we extrapolated the temperatures for Year 2 and 3 based on the temperature in Year 1, indicated by $T_{\mathrm{j}}(k)(k=1 \ldots 3, j=1 \ldots 365)$ (Fig. 1c). The daily accumulative precipitation $\left(P P_{\mathrm{j}}\right)$ and daily photoperiod $\left(S D_{\mathrm{j}}\right)$ on the $j$ th day of the year as required model parameters were processed in the same manner, as shown in Eqs. (3) and (4).

$$
\begin{aligned}
& P P_{j}=\frac{1}{35} \sum_{i=1}^{35} P P_{j}^{i}, j=1, \ldots, 365 \\
& S D_{j}=\frac{1}{35} \sum_{i=1}^{35} S D_{j}^{i}, j=1, \ldots, 365
\end{aligned}
$$

\section{Design of warming patterns}

Research on global warming has found the warming effect is uneven across geographical scales as well as over 


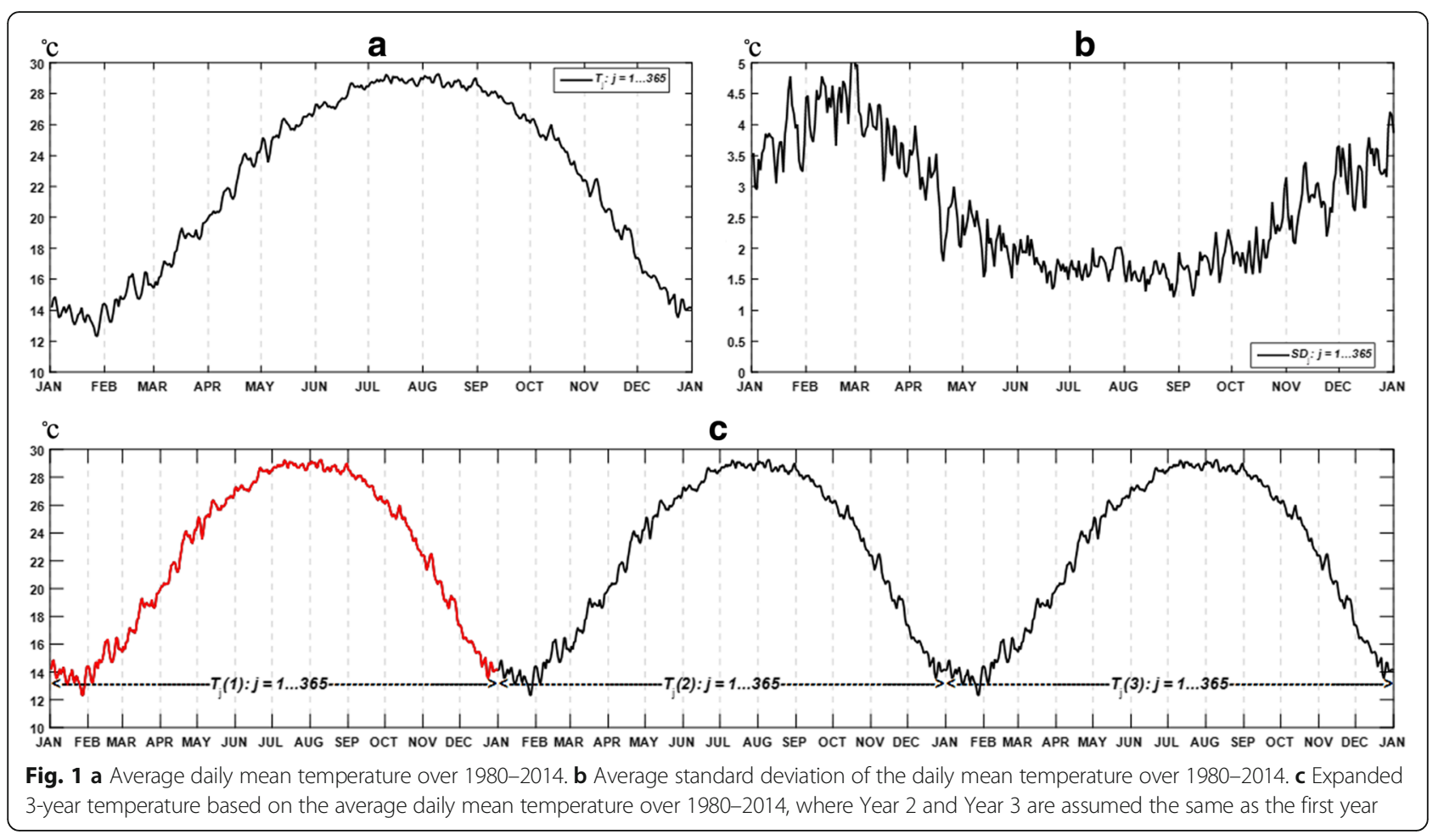

different seasons, where the winter season at high latitudes manifests the highest level of increase [24]. Existing studies on the projected climatic suitability of mosquitoes are invariably focused on the long-term, regional impact, whereas the short-term, temporal variance has been less explored [14, 16, 20, 38]. Mosquitoes as a typical ectotherm are highly susceptible to ambient temperatures; and therefore, their physiological responses and strategic adaptations to regional warming are more complex than a simple linear pattern [39]. Specifically, seasonality is a significant indicator of the warming tolerance as well as the thermal limits of ectotherms, constraining the development, reproduction, dormancy and migration of the population [39]. To explore the intricacy of seasonal responses, we systematically adjusted the temperatures of selected seasons in order to identify the impact on the second year (Year 2) and the third year (Year 3) populations. According to Fig. 1b, the local temperature fluctuated within a $5{ }^{\circ} \mathrm{C}$ range over the past 35 years. We then considered the temperature increase $(\Delta T)$ to be a variable ranging from 0.5 to $5{ }^{\circ} \mathrm{C}$ at an interval of $0.5{ }^{\circ} \mathrm{C}$, which is a slightly broader range than an estimated global temperature rise by 1.8 to $4{ }^{\circ} \mathrm{C}$ in the decade to come [40].

To explore how seasonality affects the development of Ae. albopictus, we strategically designed four warming categories, as given below:

- All-year warming (YW): increasing the temperature by $\Delta T$ for all four seasons.
- Single-season warming (SW1): increasing the temperature by $\Delta T$ for a single season.

- Two-season warming (SW2): increasing the temperature by $\Delta T$ for two selected seasons.

- Three-season warming (SW3): increasing the temperature by $\Delta T$ for three selected seasons.

By considering different seasonal combinations under each category, we generated a total of fifteen seasonal warming patterns, representing the complex nature of global warming. The selected warming months to be tested and their temporal divides in DOY are given in Table 3, where the temperature adjustments are mostly in Year 2.

By implementing the adjusted temperatures into the MPAD model, results regarding the Ae. albopictus population dynamics can be simulated and derived. The paper mainly explores the phase of blood-fed adults, as it is the most critical step for the mosquito to complete a gonotrophic cycle and transition into a viral vector [41]. We derived the following variables to describe the nature and growth of blood-fed adults:

- Blood-fed adult population $A_{\mathrm{b}}(j, \Delta T)$ : defined as the daily population of blood-fed adults when the temperature increases by $\Delta T(1 \leq j \leq 365, \Delta T=$ 0:0.5:5 $\left.{ }^{\circ} \mathrm{C}\right)$.

- Peak value $P_{\mathrm{Ab}}(\Delta T)$ : defined as the maximum daily population in a life cycle when the temperature increases by $\Delta T$. 
Table 3 Warming patterns and their included warming months

\begin{tabular}{|c|c|c|}
\hline Warming pattern & Selected warming months & $\begin{array}{l}\text { Adjusted temperature } \\
(j=\text { DOY })\end{array}$ \\
\hline YW & January-December, $2^{\text {nd }}$ year & $T_{j}(2)+\Delta T^{a}, j=1-365$ \\
\hline SW1-Spr & March-May, $2^{\text {nd }}$ year & $T_{j}(2)+\Delta T_{,} j=60-151$ \\
\hline SW1-Sum & June-August, $2^{\text {nd }}$ year & $T_{j}(2)+\Delta T_{,} j=152-243$ \\
\hline SW1-Aut & September-November, $2^{\text {nd }}$ year & $T_{j}(2)+\Delta T_{,} j=244-304$ \\
\hline SW1-Win & December, $2^{\text {nd }}$ year; January-February, $3^{\text {rd }}$ year & $\begin{array}{l}T_{j}(2)+\Delta T_{1} j=305-365 \\
T_{j}(3)+\Delta T_{,} j=1-59\end{array}$ \\
\hline SW2-Spr-Sum & March-August, $2^{\text {nd }}$ year & $T_{j}(2)+\Delta T_{,} j=60-243$ \\
\hline SW2-Spr-Aut & March-May; September-November, $2^{\text {nd }}$ year & $\begin{array}{l}T_{j}(2)+\Delta T_{,} j=60-151 \\
T_{j}(2)+\Delta T_{,} j=244-304\end{array}$ \\
\hline SW2-Sum-Aut & June-November, $2^{\text {nd }}$ year & $T_{j}(2)+\Delta T_{,} j=152-304$ \\
\hline SW2-Sum-Win & June-August and December, $2^{\text {nd }}$ year; January-February, $3^{\text {rd }}$ year & $\begin{array}{l}T_{j}(2)+\Delta T_{,} j=152-243 \\
T_{j}(2)+\Delta T_{,}=305-365 \\
T_{j}(3)+\Delta T_{,} j=1-59\end{array}$ \\
\hline SW2-Aut-Win & September-December, $2^{\text {nd }}$ year; January-February, $3^{\text {rd }}$ year & $\begin{array}{l}T_{j}(2)+\Delta T_{1} j=244-365 \\
T_{j}(3)+\Delta T_{,} j=1-59\end{array}$ \\
\hline SW2-Win-Spr & December, $2^{\text {nd }}$ year; January-May, $3^{\text {rd }}$ year & $\begin{array}{l}T_{j}(2)+\Delta T_{,} j=305-365 \\
T_{j}(3)+\Delta T_{,}=1-151\end{array}$ \\
\hline SW3-Sum-Aut-Win & June-December, $2^{\text {nd }}$ year; January-February, $3^{\text {rd }}$ year & $\begin{array}{l}T_{j}(2)+\Delta T_{,} j=152-365 \\
T_{j}(3)+\Delta T_{,} j=1-59\end{array}$ \\
\hline SW3-Aut-Win-Spr & September-December, $2^{\text {nd }}$ year; January-May, $3^{\text {rd }}$ year & $\begin{array}{l}T_{j}(2)+\Delta T_{,} j=244-365 \\
T_{j}(3)+\Delta T_{,} j=1-151\end{array}$ \\
\hline SW3-Win-Spr-Sum & December, $1^{\text {st }}$ year; January-August, $2^{\text {nd }}$ year & $\begin{array}{l}T_{j}(1)+\Delta T_{,} j=305-365 \\
T_{j}(2)+\Delta T_{,} j=1-243\end{array}$ \\
\hline SW3-Spr-Sum-Aut & March-November, $2^{\text {nd }}$ year & $T_{j}(2)+\Delta T_{,} j=60-304$ \\
\hline
\end{tabular}

${ }^{a} \Delta T$ is the temperature increase by $0.5-5^{\circ} \mathrm{C}$ at an interval of $0.5^{\circ} \mathrm{C}$

Abbreviations: Aut autumn, Spr spring, Sum summer, Win winter

- Peak time $t_{\mathrm{p}}(\Delta T)$ : defined as the DOY when $P_{\mathrm{Ab}}$ appears.

- Emergence time $t_{\mathrm{e}}(\Delta T)$ : defined as the DOY when the ratio of $A_{\mathrm{b}}$ to $P_{\mathrm{Ab}}$ first exceeds $10 \%$ as the temperature increases by $\Delta T$.

- Exit time $t_{\mathrm{d}}(\Delta T)$ : defined as the DOY when the ratio of $A_{\mathrm{b}}$ to $P_{\mathrm{Ab}}$ first drops below $10 \%$ as the temperature increases by $\Delta T$.

- Percentage change of peak value $V_{\text {peak }}(\Delta T)$ : defined as the change of peak value in relation to the unadjusted peak value as the temperature increases by $\Delta T$, as shown in Eq. (5).

$V_{\text {peak }}=V_{\text {peak }}(\Delta T)=\frac{P_{\mathrm{Ab}}(\Delta T)-P_{\mathrm{Ab}}(0)}{P_{\mathrm{Ab}}(0)}$.

- Percentage change of population abundance $V_{\text {amount }}$ $(\Delta T)$ : defined as the change of blood-fed population abundance in relation to the unadjusted blood-fed adult population, as shown in Eq. (6).

$$
\begin{aligned}
V_{\text {amount }}= & V_{\text {amount }}(\Delta T) \\
= & \frac{\sum_{j=t_{\mathrm{e}}}^{t_{\mathrm{d}}} A_{\mathrm{b}}(j, \Delta T)-\sum_{j=t_{\mathrm{e}}}^{t_{\mathrm{d}}} A_{\mathrm{b}}(j, 0)}{\sum_{j=t_{\mathrm{e}}}^{t_{\mathrm{d}}} A_{\mathrm{b}}(j, 0)} .
\end{aligned}
$$

\section{Results}

By plugging each of the fifteen warming patterns into the MPAD model and adjusting the temperature by $\Delta T\left(0.5-5{ }^{\circ} \mathrm{C}\right)$, new population curves as a function of DOY were derived. Here we mainly explore the effects of one YW pattern (Figs. 2 and 3) and four SW1 warming patterns (Figs. 4 and 5), while the results for SW2 (Additional file 1: Figure S1) and SW3 (Additional file 1: Figure S2) patterns are given in Additional file 1 . We also performed a regression analysis for each of the population variables $\left(t_{\mathrm{p}}, t_{\mathrm{e}}, t_{\mathrm{d}}, V_{\text {peak }}\right.$ and $V_{\text {amount }}$ ) as a function of $\Delta T$ and achieved a relatively good model fitting. These results are given in Additional file 2 . 


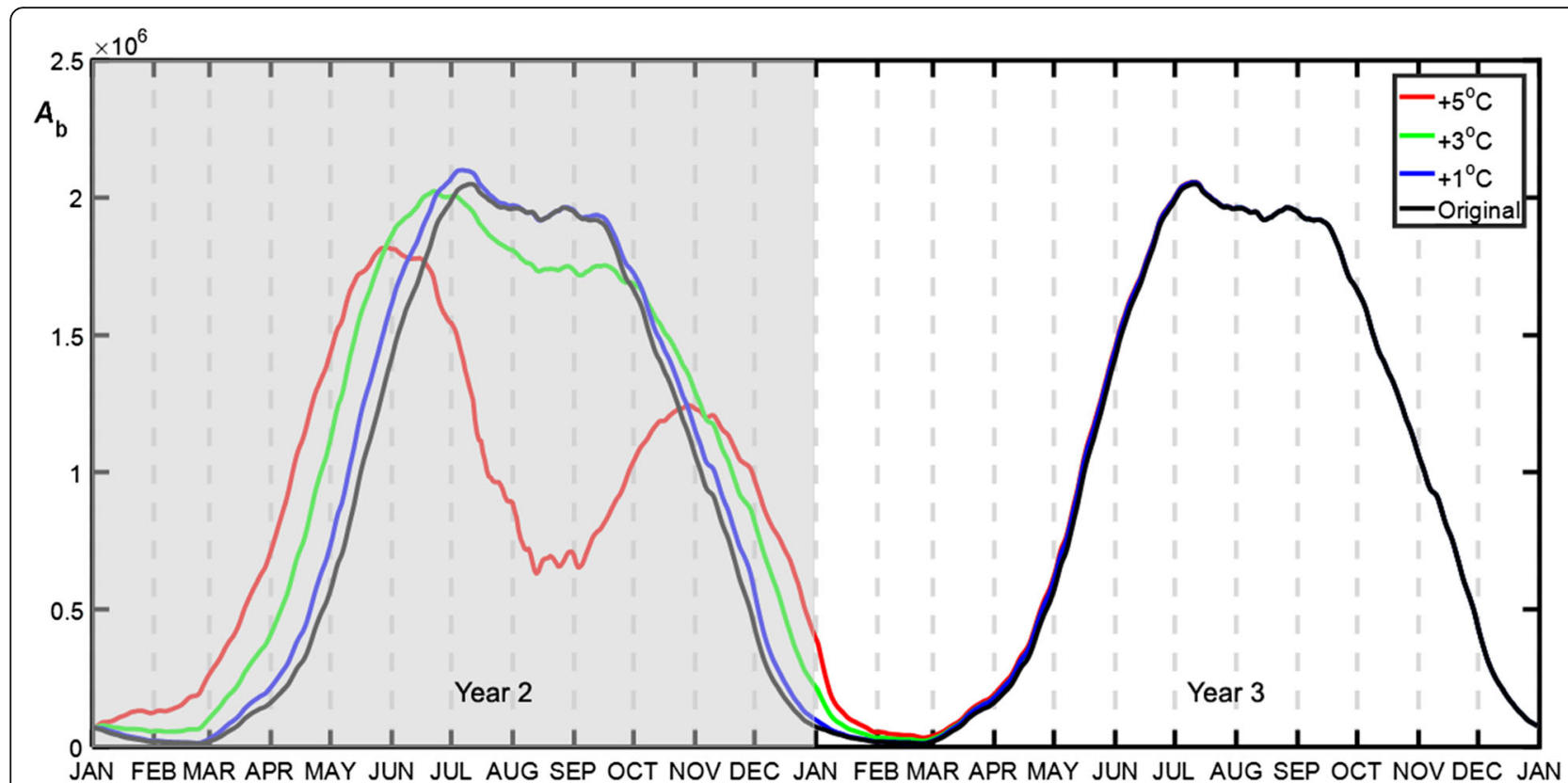

Fig. 2 Blood-fed adult population $\left(A_{b}\right)$ by implementing the all-year warming pattern with $\triangle T=1,3$ and $5{ }^{\circ} \mathrm{C}$, respectively. The shaded area represents the warming period

\section{All-year warming (YW)}

Figure 2 shows the population dynamics of the bloodfed adults before and after the temperature increases in Year 2. Compared to the original population curve (black line), the all-year warming scenario had very contrasting effects on the population abundance of Year 2: a minor increase by $\Delta T=1{ }^{\circ} \mathrm{C}$ facilitated the development to a limited extent, where the peak population surfaced in July $(\mathrm{DOY}=188)$; a drastic increase (e.g. $5{ }^{\circ} \mathrm{C}$ ) reshaped the thermal reaction and caused a noticeable drop in late summer. However, the temperature increase in Year 2 did not have a cascading effect on Year 3 for
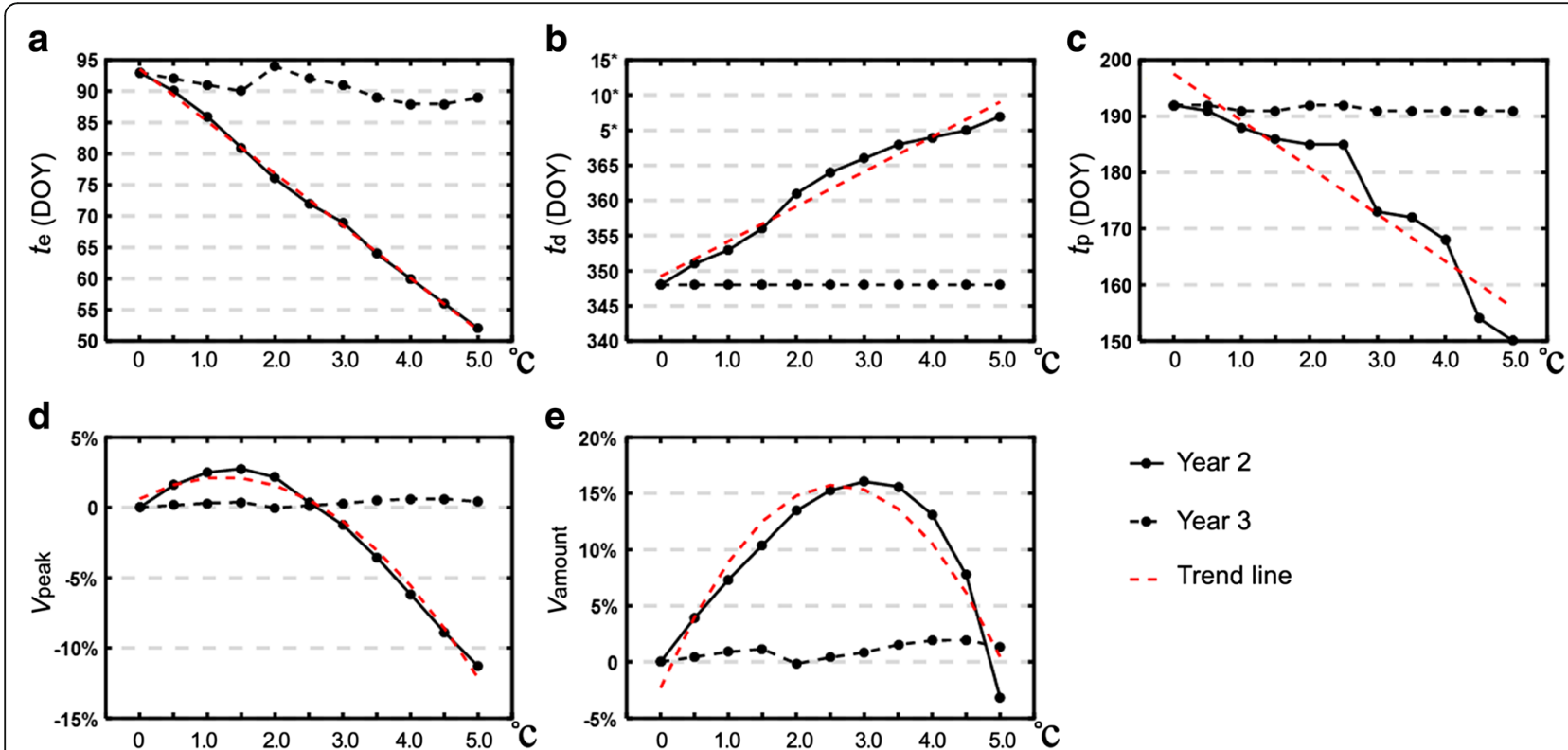

Fig. 3 Attributes of blood-fed adult population in Year 2 and Year 3 with respect to $\Delta T$ in the YW pattern. The shaded area is the warming period. The attributes include: a emergence time $\left(t_{\mathrm{e}}\right)$ in DOY; $\mathbf{b}$ exit time $\left(t_{\mathrm{d}}\right)$ in DOY; $\mathbf{c}$ peak time $\left(t_{\mathrm{p}}\right)$ in DOY; $\mathbf{d}$ percentage change of peak value $\left(V_{\text {peak }}\right)$; and e percentage change of population abundance $\left(V_{\text {amount }}\right)$ 

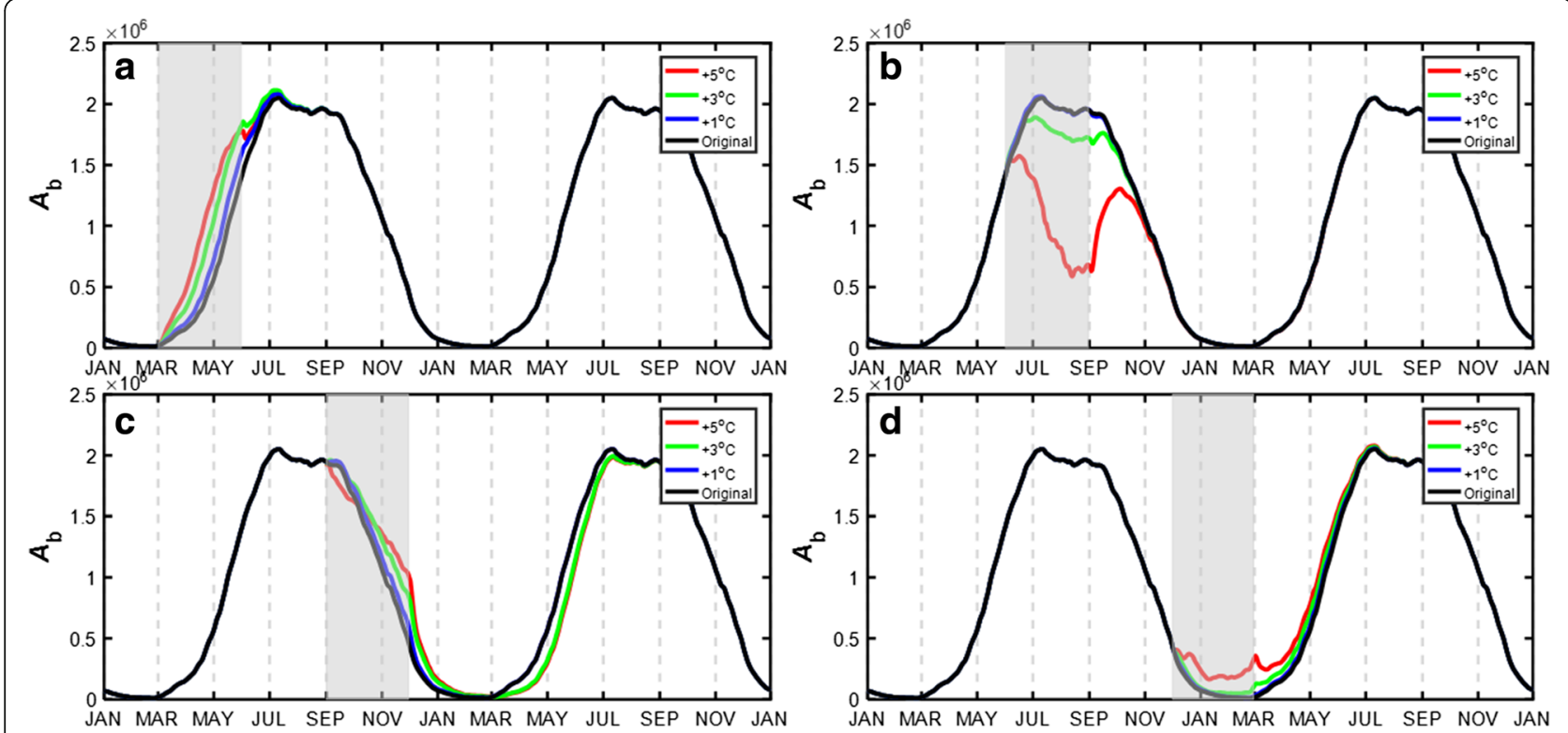

Fig. 4 Blood-fed adult population $\left(A_{b}\right)$ by implementing the single-season warming pattern of: a SW1-Spring; b SW1-Summer; c SW1-Autumn; and $\mathbf{d}$ SW1-Winter with $\Delta T=1,3$ and $5{ }^{\circ} \mathrm{C}$, respectively. The shaded area represents the warming period

the most part, whereas only the first 3 months of Year 3 were affected.

Figure 3 shows the five metrics of the blood-fed adults' development cycle with respect to the degree of warming in Year 2. It can be seen from the diagram that the modulated temperature had a marked influence on the population dynamics of Year 2, whereas Year 3 was less affected. The temperature had an overarching effect on the development period by shifting it to an earlier emergence time $t_{\mathrm{e}}$ (Fig. 3a) and a later exit time $t_{\mathrm{e}}$ (Fig. 3b). The peak time $t_{\mathrm{p}}$ had a quasi-linear relationship with $\Delta T$; and it was advanced by a maximum of 42 days at

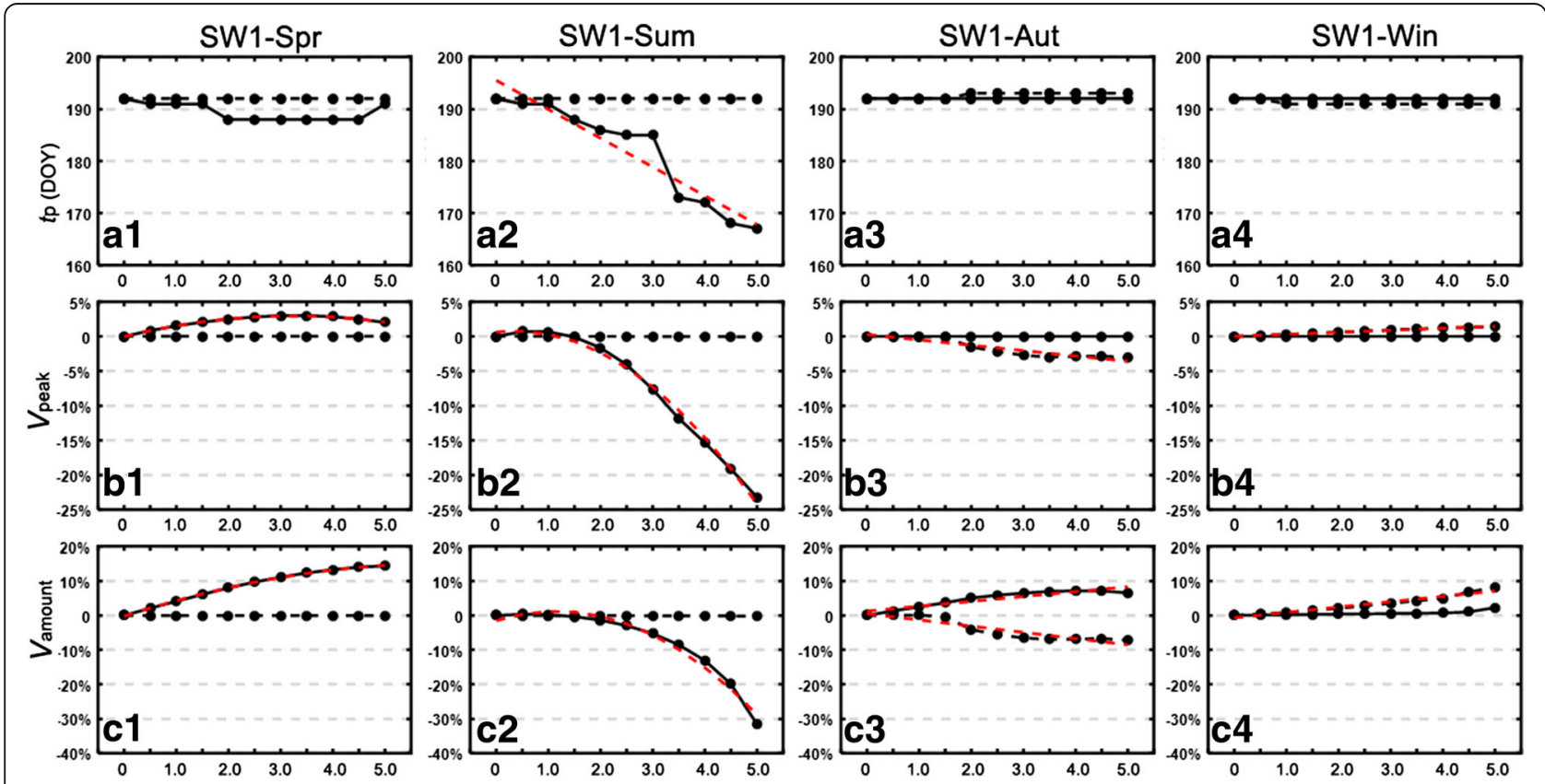

Fig. 5 Attributes of blood-fed adult population in Year 2 and Year 3 with respect to $\Delta T$ in the four SW1 patterns. The shaded area represents the warming period. The attributes include: peak time $\left(t_{\mathrm{p}}\right)$ in DOY, percentage change of peak value $\left(V_{\text {peak }}\right)$ and percentage change of population abundance $\left(V_{\text {amount }}\right)$ 
$\Delta T=5{ }^{\circ} \mathrm{C}$ (Fig. 3c). A curvilinear relationship was identified between $\Delta T$ and the percentage change of the peak value $V_{\text {peak }}$ (Fig. 3d) as well as between $\Delta T$ and the percentage change of population abundance $V_{\text {amount }}$ (Fig. 3e), where the peak of $V_{\text {peak }}(2.8 \%)$ appeared at $\Delta T$ $=1.5{ }^{\circ} \mathrm{C}$ and that of $V_{\text {amount }}(16.0 \%)$ at $\Delta T=3.0^{\circ} \mathrm{C}$.

\section{Single-season warming (SW1)}

Figure 4 shows the warming effect in a single season on the population abundance. The increased temperature facilitated the development in all seasons but summer, where the curve showed two peaks with different magnitudes (Fig. 4b). This pattern became most evident as the temperature rose by $\Delta T=5.0^{\circ} \mathrm{C}$. The spring increase expedited the early growth of the population by advancing the emergence time by a maximum of 24 days at $\Delta T=$ $5.0{ }^{\circ} \mathrm{C}$ (Fig. 4a); the autumn increase slightly postponed the exit time by a maximum of 15 days at $\Delta T=5.0{ }^{\circ} \mathrm{C}$ (Fig. 4c). In addition, the impact on Year 3 was generally very minor except autumn and winter: the autumn increase caused a slight drop of the population from March through August in Year 3 (Fig. 4c); and the winter increase facilitated the development from January through July in Year 3 (Fig. 4d).

Figure 5 shows three major indices regarding the population abundance. Again the effect was not pronounced in Year 3. The summer increase had a negative influence with a reduced peak value ( $V_{\text {peak }}$ down by 0 $23.2 \%$, Fig. 5b2) and a declined overall population abundance ( $V_{\text {amount }}$ down by $0-31.5 \%$, Fig. 5c2). The spring increase and winter increase had a positive influence on the population growth (spring: $V_{\text {peak }}$ up by $0-3.0 \%$, Fig. 5b1, $V_{\text {amount }}$ up by $0-14.4 \%$, Fig. $5 \mathrm{c} 1$; winter: $V_{\text {peak }}$ up by $0-2.2 \%$, Fig. 5 b $4, V_{\text {amount }}$ up by $0-8.2 \%$, Fig. 5 c 4 ), whereas the effect was relatively mixed for the autumn increase.

\section{Discussion}

As an extension of the MPAD model, the paper provides a new perspective to examine how the mosquito Ae. albopictus responds to warming temperatures, a problem that raises both ecological and epistemological concerns. To accommodate former studies that established the thermal reaction norms using controlled experiments [42], this study is the first to explore the seasonality of warming effects on Ae. albopictus adults implemented in a mechanistic population model. One persisting issue in controlled experiments and field surveys is that monitoring mosquito adults is relatively difficult; and the larval/pupal surveillance may misrepresent the adult population abundance $[43,44]$. To this end, the established MPAD model is able to simulate and elucidate the nature of the thermal reaction at each phase of the life cycle while providing corroborating evidence of how the seasonality affects the overall population abundance.

The historical pattern of global warming manifests temporal fluctuations, characterized by warmer winter temperatures at northern latitudes [23, 24, 45]. The effect of winter warming comes with an early arrival of both spring and winter, extending the favorable period for mosquitoes to grow, develop and reproduce [42]. This physiological response involves both altered life histories and thermal adaptations to seasonality [46]. For this reason, the simulation of the warming effect cannot be treated homogeneously in any effort to evaluate or predict impacts on mosquitoes of different global species or genera [47]. The designed seasonal warming patterns become necessary to evidence how seasonal warming impedes or promotes Ae. albopictus growth in an annual development cycle. The short-term temperature variance as exemplified in the paper has a marked influence on the life cycle of epidemic vectors beyond the effects of long-term climate change [48-53].

By incorporating the 35-year climate dataset into the model, we have observed that the different degrees of all-year warming had very contrasting influences on the population dynamics. A modest temperature rise generally aided in the development with respect to the all-year accumulative population abundance (Fig. 3e); this effect was possibly caused by the elongated development time period the warming temperature induced (Fig. 3a, b). This finding further corroborates the fact that the projected planetary temperature rise of less than $2{ }^{\circ} \mathrm{C}$ in the years to come [54] will likely facilitate the mosquito growth in most world regions and promote its expansion to areas that are currently unfavorable. However, as the temperature continued to rise, the summer growth was inhibited. The intervening effect could be explained by laboratory controlled experiments that the preferable temperature range for Ae. albopictus adults to survive is $15-30{ }^{\circ} \mathrm{C}$ and the temperature of natural eradication is over $36{ }^{\circ} \mathrm{C}$ [55]. Thus, the summer temperature increase even to a small extent will exponentially raise the mortality rate and cause the population to plummet. This trend is also evidenced by research on the species in tropics and subtropics that the annual population dynamics has two peaks and a trough in summer [56, 57].

We have also observed that the different seasonal warming patterns mediated the development process very differently. The change of population abundance in all seasons but summer is possibly induced by the effect on diapause, a state of the mosquito eggs being dormant in winter in response to adverse environmental conditions $[17,58]$. Typically, when the temperature drops below $9.5{ }^{\circ} \mathrm{C}, \mathrm{Ae}$. albopictus eggs transition into diapause and become completely inactive [59]. As the simulations illustrate, spring warming breaks the dormancy of 
diapause eggs and allows them to hatch earlier; autumn warming slightly extends the favorable period for reproduction and delays the diapause. However, these warming effects rendered cannot carry over to the following year. This result is very likely the effect of winter when the mosquito fully ceases from development and survives in terms of diapause eggs [17]. In addition, winter warming shortens the period of diapause. These effects are also evident in the SW2 and SW3 warming patterns, as shown in Additional file 1.

Admittedly, this study is flawed in several aspects. First, the design of the simulations assumes that the increased degree of temperature over the warming period is uniform. This assumption deviates from the uncertainties involved in global warming that the temperature rise is historically uneven on a daily basis and is documented with regional complications [23, 54]. To address the issue, future research on simulating the influence of warming should account for the natural fluctuating temperatures derived from historical climate data or projected by regional climate models [60]. Secondly, although both temperature and precipitation have been incorporated, the warming effects discussed in the paper only include temperature. In an atmospheric context, the change of the temperature gradient could contingently alter other climatic factors, including precipitation and humidity [2]. The constituent elements of global warming as predicted by scenarios in the Representative Concentration Pathways [61] and stochastic climatic conditions [62] should both be considered in the simulation as a way to improve the rigor of the model. Thirdly, an overlooked facet in the analysis is the evolutionary adaptation of the mosquito to climate change as a longterm shift in weather conditions [63]. The mechanistic link between population abundance and temperature is mediated by evolutionary responses that allow the mosquito to genetically evolve and facilitate its adaptation to warmer weathers and higher degrees of desiccation $[64,65]$. Future research on evaluating and projecting the climatic suitability should take a precautionary approach to examining the yearly difference in the life cycle under similar climatic conditions.

\section{Conclusions}

The rising presence and rapid expansion of dengue fever in the last few decades has raised considerable concerns about the nature and cause of the epidemic resurgence [66]. Although it is generally understood that global warming plays a potential role in increasing the incidence and geographical range of the disease [2], how climatic factors mechanistically alter the prevalence of the disease is a less elucidated territory with much complexity. In addition to human factors that increase vectorhost interaction, the dengue transmission is dictated by the population dynamics of the vector Ae. albopictus mosquitoes. Our simulations with the 35-year climate data in a mathematical model show that the mosquito's life cycle is sensitive to seasonal warming in different ways, where the development is inhibited by summer warming but is facilitated by both spring and winter warming. In this regard, the projected warming to a modest degree in future decades will most likely promote the growth and expansion of the species in high-latitude regions. Understanding this temperaturedriven mechanism as one chain of the transmission events is critical to refining the thermal reaction norms of epidemic vectors under global warming as well as developing effective mosquito prevention and control strategies.

\section{Additional files}

Additional file 1: Two-season (SW2) and three-season (SW3) warming patterns. (DOCX $16 \mathrm{~kb}$ )

Additional file 2: Regression analysis of the warming effects. (DOCX $14 \mathrm{~kb}$ )

\begin{abstract}
Abbreviations
DOY: Day of year; MPAD: Mechanistic population model of Ae. albopictus with diapause; SW1: Sinlge-season warming; SW2: Two-season warming; SW3: Three-season warming; YW: All-year warming
\end{abstract}

\section{Acknowledgements}

Not applicable.

\section{Funding}

The research was financially supported by National Key Basic Research and Development Plan (2012CB955501) of China Ministry of Science and Technology. The research was financially supported by National Natural Science Foundation of China (81273139) of China Ministry of Science and Technology.

\section{Availability of data and materials}

The dataset containing daily mean temperature and daily mean accumulative precipitation (1980-2014) supporting the conclusions of this article is available in the China Meteorological Data Sharing Service System repository, http://data.cma.cn/data/detail/dataCode/A.0029.0001.html. The dataset of photoperiod supporting the conclusions of this article is available in the National Oceanic and Atmospheric Administration repository with respect to the coordinate of the study area, http://www.srrb.noaa.gov/ highlights/sunrise/calcdetails.html.

\section{Authors' contributions}

PJ formulated the mechanistic population model, performed the statistical analysis and drafted the manuscript. XC led the research by creating a research agenda and restructuring the manuscript. JC offered suggestions on incorporating the climatic datasets into the model and proposed methodological directions for data analysis. $L L$ coordinated the field data collection in Shanghai and Guangzhou, China. QL helped with evaluating the model. XT assisted with data analysis. All authors read and approved the final manuscript.

\section{Competing interests}

The authors declare that they have no competing interests.

Consent for publication

Not applicable. 


\section{Ethics approval and consent to participate}

Not applicable.

\begin{abstract}
Author details
${ }^{1}$ College of Global Change and Earth System Science, Beijing Normal University, Beijing 100875, China. ${ }^{2}$ State Key Laboratory of Earth Surface Processes and Resource Ecology, Beijing Normal University, Beijing 100875, China. ${ }^{3}$ Department of Emergency Management, Arkansas Tech University, Russellville 72801, AR, USA. ${ }^{4}$ National Institute for Communicable Disease Control and Prevention, China CDC, Beijing 102206, China.
\end{abstract}

\section{Received: 11 September 2016 Accepted: 28 February 2017} Published online: 11 March 2017

\section{References}

1. Githeko AK, Lindsay SW, Confalonieri UE, Patz JA. Climate change and vector-borne diseases: a regional analysis. Bull World Health Organ. 2000; 78(9):1136-47.

2. Reiter P. Climate change and mosquito-borne disease. Environ Health Perspect. 2001;109 Suppl 1:141.

3. Knudsen A. Global distribution and continuing spread of Aedes albopictus. Parassitologia. 1995;37(2-3):91-7.

4. Laird M, Calder L, Thornton RC, Syme R, Holder P, Mogi M. Japanese Aedes albopictus among four mosquito species reaching New Zealand in used tires. J Am Mosq Control Assoc. 1994;10(1):14-23.

5. Reiter $P$, Sprenger $D$. The used tire trade: a mechanism for the worldwide dispersal of container breeding mosquitoes. J Am Mosq Control Assoc. 1987;3(3):494-501.

6. Hales S, De Wet N, Maindonald J, Woodward A. Potential effect of population and climate changes on global distribution of dengue fever: an empirical model. Lancet. 2002;360(9336):830-4.

7. Bhatt S, Gething PW, Brady OJ, Messina JP, Farlow AW, Moyes CL, et al. The global distribution and burden of denque. Nature. 2013:496(7446):504-7.

8. Brady OJ, Gething PW, Bhatt S, Messina JP, Brownstein JS, Hoen AG, et al. Refining the global spatial limits of dengue virus transmission by evidencebased consensus. Plos Negl Trop Dis. 2012;6(8):897-8.

9. Gratz NG. Critical review of the vector status of Aedes albopictus. Med Vet Entomol. 2004;18(3):215-27.

10. World Health Organization. Dengue and severe dengue. 2016. http://www. who.int/mediacentre/factsheets/fs117/en/. Accessed 22 Feb 2017.

11. Novak R. The Asian tiger mosquito, Aedes albopictus. Wing Beats. 1992;3(5):1.

12. Enserink M. A mosquito goes global. Science. 2008;320(5878):864-6.

13. Medlock JM, Hansford KM, Schaffner F, Versteirt V, Hendrickx G, Zeller $H_{\text {, et }}$ al. A review of the invasive mosquitoes in Europe: ecology, public health risks, and control options. Vector Borne Zoonotic Dis. 2012;12(6):435-47.

14. Caminade C, Medlock JM, Ducheyne E, McIntyre KM, Leach S, Baylis M, et al. Suitability of European climate for the Asian tiger mosquito Aedes albopictus: recent trends and future scenarios. J R Soc Interface. 2012;9: 2708-17.

15. Scholte E-J, Schaffner F. Waiting for the tiger: establishment and spread of the Aedes albopictus mosquito in Europe. In: Takken W, Knols B, editors. Emerging pests and vector-borne diseases in Europe. Wageningen: Wageningen Academic Publishers; 2007. p. 241-60.

16. Fischer D, Thomas SM, Niemitz F, Reineking B, Beierkuhnlein C. Projection of climatic suitability for Aedes albopictus Skuse (Culicidae) in Europe under climate change conditions. Glob Planet Chang. 2011;78(1):54-64.

17. Hawley WA. The biology of Aedes albopictus. J Am Mosq Control Assoc Suppl. 1988;1:1-39.

18. Alto BW, Juliano SA. Temperature effects on the dynamics of Aedes albopictus (Diptera: Culicidae) populations in the laboratory. J Med Entomol. 2001:38(4):548-56.

19. Alto BW, Juliano SA. Precipitation and temperature effects on populations of Aedes albopictus (Diptera: Culicidae): implications for range expansion. J Med Entomol. 2001;38(5):646-56

20. Roiz D, Rosa R, Arnoldi D, Rizzoli A. Effects of temperature and rainfall on the activity and dynamics of host-seeking Aedes albopictus females in northern Italy. Vector Borne Zoonotic Dis. 2010;10(8):811-6.

21. Loetti $V$, Schweigmann N, Burroni N. Temperature effects on the immature development time of Culex eduardoi Casal \& García (Diptera: Culicidae). Neotrop Entomol. 2011;40(1):138-42.
22. Madder DJ, Surgeoner GA, Helson BV. Number of generations, egg production, and developmental time of Culex pipiens and Culex restauns (Diptera: Culicidae) in southern Ontario. J Med Entomol. 1983;20(3):275-87.

23. Serreze MC, Walsh JE, Chapin FS, Osterkamp T, Dyurgerov M, Romanovsky V, et al. Observational evidence of recent change in the northern high-latitude environment. Clim Change. 2000;46(1-2):159-207.

24. O'Brien $\mathrm{KL}$, Leichenko RM. Double exposure: assessing the impacts of climate change within the context of economic globalization. Global Environ Chang. 2000;10(3):221-32.

25. Jia P, Lu L, Chen X, Chen J, Guo L, Yu X, Liu Q. A climate-driven mechanistic population model of Aedes albopictus with diapause. Parasit Vectors. 2016; 9(1):1-15.

26. Shen J, Luo L, Li L, Jing Q, Ou C, Yang Z, et al. The impacts of mosquito density and meteorological factors on dengue fever epidemics in Guangzhou, China, 2006-2014: a time-series analysis. Biomed Environ Sci. 2015;28(5):321-9.

27. Lei L, Li X, Xiao X, Xu Y, Huang M, Yang Z. Identification of Aedes albopictus larval index thresholds in the transmission of dengue in Guangzhou, China. J Vector Ecol. 2015:40(2):240-6.

28. China Meteorological Data Sharing Service System. China. 2016. http://data. cma.cn/data/detail/dataCode/A.0029.0001.html. Accessed 23 Nov 2016.

29. National Oceanic And Atmospheric Administration: Solar Calculation Details. http://www.srrb.noaa.gov/highlights/sunrise/calcdetails.html (2017). Accessed 22 Feb 2017.

30. Cailly P, Tran A, Balenghien T, L'Ambert G, Toty C, Ezanno P. A climatedriven abundance model to assess mosquito control strategies. Ecol Model. 2012;227:7-17.

31. Erickson RA, Presley SM, Allen LJ, Long KR, Cox SB. A stage-structured, Aedes albopictus population model. Ecol Model. 2010;221(9):1273-82.

32. Tran A, L'Ambert G, Lacour G, Benoit $R$, Demarchi M, Cros $M$, et al. A rainfalland temperature-driven abundance model for Aedes albopictus populations. Int J Environ Res Public Health. 2013;10(5):1698-719.

33. Clements A. The biology of mosquitoes: sensory, reception and behaviour. Oxon: CABI Publishing; 1999.

34. Chapman RF. The insects: structure and function. Cambridge: Cambridge University Press; 1998

35. Tauber MJ, Tauber CA, Masaki S. Seasonal adaptations of insects. Oxon: Oxford University Press; 1986.

36. Luciano T, Severini IF, Di Luca IM, Bella IA, ryP Roberto R. Seasonal patterns of oviposition and egg hatching rate of Aedes albopictus in Rome. J Am Mosq Control Assoc. 2003;19(1):100

37. Jia P. Python code for the MPAD model. 2017. https://github.com/J-Phx13/ Albopictus-Model/blob/master/Albopictus_Simulation.py. Accessed 22 Feb 2017.

38. Medlock JM, Avenell D, Barrass I, Leach S. Analysis of the potential for survival and seasonal activity of Aedes albopictus (Diptera: Culicidae) in the United Kingdom. J Vector Ecol. 2006;31(2):292-304.

39. Deutsch CA, Tewksbury JJ, Huey RB, Sheldon KS, Ghalambor CK, Haak DC, et al. Impacts of climate warming on terrestrial ectotherms across latitude. Proc Natl Acad Sci USA. 2008;105(18):6668-72.

40. Meehl GA, Stocker TF, Collins WD, Friedlingstein P, Gaye AT, Gregory JM, et al. Global climate projections. In: Solomon SD, Qin M, Manning Z, Chen M, Marquis KB, Averyt M, et al., editors. Climate change 2007: the physical science basis. Cambridge and New York: Cambridge University Press; 2007

41. Rezza G. Aedes albopictus and the reemergence of dengue. BMC Public Health. 2012;12(1):1-3.

42. Bradshaw WE, Zani PA, Holzapfel CM. Adaptation in temperate climate. Evolution. 2004:58(8):1748-62.

43. Chinese Center For Disease Control And Prevention: Surveillance and control of Aedes aegypti and Aedes albopictus in the United States. http://www.cdc. gov/chikungunya/resources/vector-control.html (2016). Accessed 22 Feb 2017.

44. Polwiang S. The seasonal reproduction number of dengue fever: impacts of climate on transmission. PeerJ. 2015;3(7):286-95

45. Myneni RB, Keeling CD, Tucker CJ, Asrar G, Nemani RR. Increased plant growth in the northern high latitudes from 1981 to 1991. Nature. 1997; 386(6626):698.

46. Robinet $\mathrm{C}$, Roques $\mathrm{A}$. Direct impacts of recent climate warming on insect populations. Integr Zool. 2010;5(2):132-42.

47. Vasseur DA, Delong JP, Gilbert B, Greig HS, Harley CD, McCann KS, et al. Increased temperature variation poses a greater risk to species than climate warming. Proc Biol Sci. 2014;281(1779):85-94. 
48. Bozinovic F, Bastías DA, Boher F, Clavijobaquet S, Estay SA, Jr AM. The mean and variance of environmental temperature interact to determine physiological tolerance and fitness. Physiol Biochem Zool. 2011;84(6):543-52.

49. Clusella-Trullas S, Chown SL. Climatic predictors of temperature performance curve parameters in ectotherms imply complex responses to climate change. Am Nat. 2011;177(6):738-51.

50. Martin T, Huey R. Why "Suboptimal" is optimal: Jensen's inequality and ectotherm thermal preferences. Am Nat. 2008;171(3):53-80.

51. Paaijmans KP, Heinig RL, Seliga RA, Blanford JI, Blanford S, Murdock CC, et al. Temperature variation makes ectotherms more sensitive to climate change. Glob Chang Biol. 2013;19(8):2373-80.

52. Ruel JJ, Ayres MP. Jensen's inequality predicts effects of environmental variation. Trends Ecol Evol. 1999;14(9):361-6.

53. Terblanche JS, Nyamukondiwa C, Kleynhans E. Thermal variability alters climatic stress resistance and plastic responses in a globally invasive pest, the Mediterranean fruit fly (Ceratitis capitata). Entomol Exp Appl. 2010; 137(3):304-15

54. Cao L, Zhao P, Yan Z, Jones P, Zhu Y, Yu Y, et al. Instrumental temperature series in eastern and central China back to the nineteenth century. J Geophys Res Atmos. 2013;118(15):8197-207.

55. Yang HM, Macoris ML, Galvani KC, Andrighetti MT, Wanderley DM. Assessing the effects of temperature on the population of Aedes aegypti, the vector of dengue. Epidemiol Infect. 2009;137(8):1188-202.

56. Almeida APG, Baptista SS, Sousa CA, Novo MTL, Ramos HC, Panella NA, et al. Bioecology and vectorial capacity of Aedes albopictus (Diptera: Culicidae) in Macao, China, in relation to dengue virus transmission. J Med Entomol. 2005;42(3):419-28

57. Ho BC, Chan KL, Chan YC. Aedes aegypti (L.) and Aedes albopictus (Skuse) in Singapore City: 3. Population fluctuations. Bull World Health Organ. 1971; 44(5):635-41.

58. Hanson SM. Field overwinter survivorship of Aedes albopictus eggs in Japan. J Am Mosq Control Assoc. 1995;11(3):354-7.

59. Toma L, Severini F, Di LM, Bella A, Romi R. Seasonal patterns of oviposition and egg hatching rate of Aedes albopictus in Rome. J Am Mosq Control Assoc. 2003;19(1):19-22.

60. Van Vuuren DP, Edmonds J, Kainuma M, Riahi K, Thomson A, Hibbard K, et al. The representative concentration pathways: an overview. Clim Change. 2011;109:5-31

61. Rogelj J, Meinshausen M, Knutti R. Global warming under old and new scenarios using IPCC climate sensitivity range estimates. Nat Clim Chang 2012;2(4):248-53.

62. Wilks DS, Wilby RL. The weather generation game: a review of stochastic weather models. Prog Phys Geogr. 1999;23(3):329-57.

63. Hoffmann AA, Sgro CM. Climate change and evolutionary adaptation. Nature. 2011;470(7335):479-85.

64. Kearney M, Porter WP, Williams C, Ritchie S, Hoffmann AA. Integrating biophysical models and evolutionary theory to predict climatic impacts on species' ranges: the dengue mosquito Aedes aegypti in Australia. Funct Ecol. 2009;23(3):528-38.

65. Sternberg ED, Thomas MB. Local adaptation to temperature and the implications for vector-borne diseases. Trends Parasitol. 2014;30(3):115-22.

66. Hopp MJ, Foley JA. Worldwide fluctuations in dengue fever cases related to climate variability. Clim Res. 2003;25(1):85-94.

\section{Submit your next manuscript to BioMed Central and we will help you at every step:}

- We accept pre-submission inquiries

- Our selector tool helps you to find the most relevant journal

- We provide round the clock customer support

- Convenient online submission

- Thorough peer review

- Inclusion in PubMed and all major indexing services

- Maximum visibility for your research

Submit your manuscript at www.biomedcentral.com/submit
C Biomed Central 